\title{
The Economy of Cosmic Power: A Vision for a Daoist Theology of Religion
}

\author{
James Miller ${ }^{1}$ \\ Queen's University, Canada \\ Published in Theology in Global Context: Essays in Honor of Robert Cummings \\ Neville edited by Amos Yong and Peter Heltzel: Edinburgh: T\&T Clark 2004.
}

One of Robert Cummings Neville's lasting achievements, apart from providing a new and novel argument for the existence of God and participating in the resurrection of Charles Sanders Pierce, has been the dogged persistence with which he has pursued the study of religion in order to divine the truth about ultimate reality. Such truth is disclosed in the complex cultural codes by which people engage in religious practice, but is not completely exhausted or explained by such symbolic constructs. For Neville, this superabundance of meaning cannot be explained by reference to an infinitely deep web of cultural significations endlessly referring to each other in a mystical, Derridean, jewel-net of Indra, but rather points toward the power of ultimate reality which those cultural conventions engage. Religious cultures are thus not to be seen solely as diverse systems of meaning and identity-though they are that too-but also as cultural institutions for human engagement with ultimate reality.

The study of Daoism benefits from this Nevillean approach to religion because Daoism takes as its foundation not the mythical narrative of some skydwelling persona, but the natural power of transformation that lies within our bodies, our environment and the stars in the sky, and which ultimately enfolds us in a transcendent matrix of cosmic creativity known as Dao. Although Daoism did develop complex mythologies, particularly surrounding the figures of Laozi, Lü

${ }^{1}$ James Miller graduated from the PhD program at Boston University in 2000 and is now Assistant Professor of East Asian Traditions in the Department of Religious Studies at Queen's University, Canada. He is the author of Daoism: A Short Introduction (Oxford: OneWorld, 2003), co-editor of Daoism and Ecology (Harvard, 2001), and editor of www.daoiststudies.org, a web resource for Daoist studies. 
Dongbin or Zhang Sanfeng, these immortal figures and deities are not seen as the foundation of the universe nor as the foundation of Daoism. Rather Daoist religion fundamentally takes place in reference to a non-personal unitary creative power that is understood as transcending its various temporal and spatial instantiations.

For this reason, Daoist studies finds itself in somewhat of a different space than many religious traditions where myths of gods who found the world take center stage. Such religious traditions can readily be interpreted as complex cultural entities where ritual action takes place in reference to mythic narratives that form the shared identity of the religious group. But in Daoism the meaning of a ritual action, such as a particular hand gesture given by a Daoist nun, may not be readily explainable by reference to any cultural or mythic context. Such a gesture is rather to be interpreted in accordance with the systems of vital power (qi) that pervade the body, and how that particular gesture stimulates the flow of $q i$ in a particular way. Such rituals, Daoists claim, are not efficacious because they refer to the complex symbolic structures of Chinese mythic consciousness, but rather because they stimulate specific physiological or energetic conditions within the body. One result of this phenomenon is that the study of Daoism finds itself somewhat marginalized in the academy precisely because this aspect of Daoist ritual resists the usual sinological or religious studies attempts to interpret Chinese religion in terms of Chinese culture and history. All this is not to discount the many ways in which Daoist religion functions in ways that are extremely well understood by traditional approaches to the study of religion and sinology. Rather it is to suggest that such explanations do not readily explain this natural claim made by Daoist practitioners. Such a claim is not founded upon the particularities of Chinese culture but on the universality of the human condition, and in particular the universal framework for experience provided by the human body (see Miller 2001). It might be argued that all claims about the naturalness of some reality are in themselves cultural claims (see LaFargue 2001), but the Daoist claim to naturalness is grounded in the universal lived experience of the human body and is particularly difficult to discount in purely cultural terms. Although Daoist interpretations of such experiences are articulated in reference 
to a sophisticated cultural view of the body, such cultural interpretations are not the same as the implicit claim of the naturalness and universality of its underlying principles. Moreover, this is a different claim than the Christian claim that Jesus will save you from the fires of hell, because that claim is grounded chiefly in faith, that is, in an expectation of some future event; ${ }^{2}$ but the Daoist claim is grounded in the present reality of transformation.

This particular feature of the Daoist experience suggests a new theory of religions, not in a grand sense, but in the Nevillean sense of a new way of looking at this aspect of religious data that is able to account for the natural claims made by Daoists in natural, that is, metaphysical terms (see Neville 1995). But before explaining this theoria, it is worthwhile reviewing a similar problem encountered by Emile Durkheim in his conclusion to the Elementary Forms of Religious Life (1995). There Durkheim wants to know why religion persists as a social fact. His explanation is that individuals seek to locate themselves in a social, i.e., religious, situation in order to be better able to live life: the faithful person "who has communed with his god is not simply a man who sees new truths that the unbeliever knows not; he is a man who is stronger" (Durkheim 1995: 419). As the translator notes, the French original for this phrase is "qui peut davantage" (original emphasis).To the religious person who is "more able", real power is imparted. Durkheim's theory is that this real power is located collectively in society and is represented in the web of symbols or collective representations that constitutes such a society. The problem with his theory is that a symbol or an idea cannot of itself add power to human life: "As rich in emotive power as an idea may be, it cannot add anything to our natural vitality; it can only release emotive forces that are already within us, neither creating nor increasing them" (Durkheim 1995: 419). Note also that, in another context, Durkheim rejects the animistic explanation of religion because he does not believe that a religion

${ }^{2}$ Even modern existential interpretations of the Christian faith must defer the full ontological reality of the Christian's existential choice to the time of the apocalypse. This secular frustration is no doubt one reason for the plethora of materialist liberation theologies that emerged in the twentieth century and for their subsequent condemnation by more orthodox Christian theologians. 
founded on the idea of an imaginary soul could perdure as religions obviously have done (1995: 45-67). If religions have persisted, there must be some real power that they place at the disposal of their adherents, otherwise people should not continue to practice religion.

For Durkheim, the source of this vital power is society itself, the "objective, universal, and eternal cause of those sui generis sensations of which religious experience is made" (1995: 421). But Durkheim famously defines society as the "idea it has of itself" (1995: 425), a definition that renders his explanation of the experience of religious power implausible: how can an idea impart an actual power that is more persistent than a mere emotional reaction?

My argument is that a fruitful strategy for explaining the power of Daoist rituals lies not in understanding them as social-cultural signs, but as transactions within an economy of cosmic power. To investigate this aspect of Daoism, therefore, is to investigate the nature of the relationship between an individual and the cosmic field of power that forms his or her cosmological context. Such a relationship may be denominated as an economy of cosmic power formed by the transactions between a person and the cosmic environment. This cosmic environment within which such transaction takes place is formed by horizons of what is ultimately important for that person. Just as there is a wide diversity of people and cultures in the world, so there is a wide diversity of "fields" that inform, structure and delimit what is important for people. This is the basis for the diversity of religious expressions in the world. But the common structure of human life also places certain limits on this diversity: all of us have bodies, and all of us die. These two common features, embodiment and mortality, describe what is universally and ultimately important for human beings, and together form the cosmic-environmental matrix that births the particular identities of human beings, and which structures and limits our existential location in spatial terms (the body) and in temporal terms (birth-death). These two axes, the spatial axis of the body-environment, and the temporal matrix of life-time, together constitute the ontogenetic matrix of each individual life. In Chinese terms, this ontogenetic matrix is known as the Dao. This ontogenetic matrix is universal in 
that it informs and enfolds all life. But it is also diverse in that each person's dao, the structures of their environment and time, is unique.

Daode jing ch. 25 offers an terse outline of how human beings are situated within the spatio-temporal matrix of the Dao.

Humans model earth.

Earth models Heaven.

Heaven models dao.

Dao models its own nature.

(Author's trans.)

This text denotes the structure of relations that obtains between human beings and their environing cosmic context. Firstly, "humans model earth." This refers to the cosmological structuring of spatial, physical location: humans are biological beings whose life is limited and enabled by their being embodied. Human life is contingent upon the life processes of the earth, its ecology and environment. Next, "earth models heaven." This denotes the temporal structuring of all biological life. The heavens mark and control our destiny, understood chiefly as the time of our birth and death. We look to the sun and the stars to mark the seasons and the years that circumscribe all biological life. With these two elements in place, the "spatial" configuring of the body and the "temporal" configuring of time and death, we have a picture of the universal pattern of a cosmological matrix ("heaven follows dao") that configures the two ultimately important axes of human life. The Way is thus the process of transformation within which all biological life functions and which orders the heavenly, temporal destiny of human beings.

Finally the text notes that "Dao models its own nature." This suggests firstly that the Dao transcends all the phenomena within the world-that the Dao takes nothing as its model except itself. It also denotes the recursive nature of the Daoist cosmos whereby the unitary, transcendent Dao is microcosmically and hologrammatically reproduced in the particular daos of each life-matrix. Each micro-dao reproduces the macro-Dao, taking it(self) as its own nature. This recursion is also explained in Daode jing ch. 42: "Dao engenders one, one engenders two, two engenders three, three engenders the ten thousand living things." Note that the one does not divide ( fen) into the two but gives birth 
(sheng) to the two. At each point in this cosmogonic movement a recursive act takes place. Dao stands for the principle of recursive generativity that produces the one. The one then takes up into itself this principle and produces two. The two then takes up into itself the one and produces the three, and so on. At each stage there appears to be more than there was before. 3 In this Daoist scheme, however, this recursive process is not to be taken as the moment of creation that stands at the beginning of time, but as the principle of creativity inherent in every moment of time. The macro-Dao, as the principle of recursion, unites all that has gone before together with the possibility of all future creativity into itself as a foundational cosmic structure that constitutes a diversity of dynamic fields of potentiality, the micro-daos that are constantly self-so (ziran). The dynamics of religious transaction depend on the possibility of the negotiation of the status of the body within its own cosmic field (dao).

In Daoist religion, this negotiation took place in two modes, one in reference chiefly to the heavens and one in reference chiefly to the earth. The purpose of negotiating with heaven was to alter one's temporal destiny, either by extending the years of one's life, or by attaining some transcendent state after death. Daoist texts, prayers and incantations, constantly refer to the desire of Daoist adepts to extend their lifespan or to undergo some sort of temporal transfiguration. Such a material desire might seem religiously childish, like a child asking Santa Claus for a new toy. Yet the Daoist tradition forces scholars with insistent regularity to confront this "cosmic secularity" of religion. When Daoist adepts recite prayers from the Scripture of the Yellow Court while engaging in the visualization of deities in the body, their goal is that "my person will not wither" (Huangting neijing jing 10:5; trans. Miller 2000: 175). This is not the same as praying that one will be delivered into the realm of eternal paradise after the "end" of secular time, but rather a prayer that the cosmic

\footnotetext{
3 This cosmogony can be contrasted with the Neo-Platonic cosmogony in which the One becomes the Many by an effervescence of differentiation. In such a scheme creation is fundamentally the creation of negations in an existing Oneness (that because of its being One is indistinguishable from Nothing). Conversely the ascent to the One proceeds by the negation of negations, that is, by negating differentiations in order to approximate more nearly the primordial fullness of the one.
} 
structures that shape the times of one's life and death be altered within the secular world. Highly complex cultural forms emerged within the Daoist tradition that sought to negotiate the framework of life and death by appeal to a vast array of celestial beings who were the cultural embodiment of the natural power of the heavens, that is, of time. These rituals of salvation can be interpreted in terms of the cultural realities of China's imperial court, but the underlying theology of negotiating with time can best be explained by appeal to the underlying cosmological principles.

The second mode of negotiation or religious transaction concerns the Daoist's physical body in its immediate environment. The nature of this meditation is both physiological as well as psychological, aiming to transfigure the vital power that flows that through the body into an ever-refined, more subtle form of $q i$. This type of meditation can in theory be carried out anywhere, but Daoists sought to situate themselves in environments, notably caves or grottos, which seem to be particularly conducive to Daoist meditation. Unlike many religions where ritual space is portable and humanly constructed (which is certainly true of many Daoist rituals), some Daoist practices seem best to be served by a "natural sacred space," that is a particular environmental location that is of cosmological benefit to human beings. Most frequently these spaces take the form of mountain caves. The Chinese word for such caverns or grottoes (dong) can be interpreted by reference to a close homonym meaning communication (tong). Caves thus function as spaces where the individual is able to have communicative access to the hidden realms of the cosmos, to the deeper recesses of cosmic power and creativity. Such caves do not seem to be chosen primarily because of their particular cultural meaning or the history associated with them, but because of the quality of space or environment that they afford to the Daoist practitioner. One scholar has written that they seem to be living and breathing features of the natural landscape that closely mirror the Daoist vision of human physiology:

Despite a singular solidity, their physical permeability in terms of air- and water-flow reflects the inner workings of the human body. Blood equals water; air equals breath. Spermatic liquids form pools; walls constitute shapes like inner organs or viscera. Their resident, left windowless and in 
an enclosed void, experiences the dignity of complete independence and autarky.

(Hahn 2000: 695)

Such caves thus form the living matrix or womb within which the adept can engage in the cultivation of her body in hologrammatic, recursive relationship to its dao (see Miller 2003). It is also important to note that many forms of Daoist cultivation should not, strictly speaking, be referred to as self-cultivation. The correct Daoist term is xiudao-cultivation of one's dao. Daoists are not New-Age self-obsessed, self-referential postmodern Westerners. They are engaged in the cultivation of transcendent potential within their cosmic context, their dao. These forms of cosmic harmony are not purely cultural harmonies, nor are they purely transcendental fantasies, but are concretely implicated in natural principles of physiology, geography and astronomy (for a discussion of these three aspects see Miller 2003).

Can this theoria of Daoist religion be applied also to the study of nonDaoist religions? The cosmic materiality of religion is in fact a firm basis for engaging in comparative theology because it rests not on the cultural diversity of religious symbol systems but on the experience of anthropocosmic embodiment. This comparative framework differs significantly from the comparative theology hitherto undertaken, which has notably focussed on the mythic, literary or symbolic output of religions. It also differs from strictly materialist or reductive approaches that ignore the power of religious rituals to inscribe human bodies in the ultimate reality of their cosmic matrix. The starting point for such a comparative theology must be the nature of the body itself as a field of cosmic transaction. Clearly one might envision many possibilities for comparatively engaging those pagan and indigenous traditions where religious power is transacted in reference to specific environmental locales. But adopting this perspective is a surprisingly fruitful way of examining the Christian tradition, because in classical Christian theology it is the resurrection of Jesus' physical body that is of cosmic significance, and it was important for Christian theologians to understand the characteristics of the resurrection body obtained by Jesus Christ. This question might seem odd to those whose vision of Christian religion is primarily spiritual. But from the perspective of the theory of the economy of 
cosmic power which I am advocating here (that the body be conceived as the field of cosmic transaction), the precise nature of the reconfigured resurrection body is a vital question for comparative theology.

According to Augustine, the problem with human bodies lies chiefly in their heaviness and corruption (de doct. Christ.1.24.24), which prevent the body from becoming a suitable vehicle for the resurrection. If the body can be transfigured so as to eliminate these two hindrances (mass and passibility) then it can be a suitable vehicle for rising to eternal life. The question of how a body can be reduced in weight and corruptibility is thus an intriguing question for Christian theologians who, like Augustine, are wedded to the material reality of the resurrection.

The question of mass is treated in chapter eleven of de civ. Dei 22. Augustine is concerned here with the Neo-Platonic ranking of Aristotle's four elements (earth, water, air and heavens) from heaviest to lightest. To this ranking Augustine steals a clue from his Manichaean past, adding "soul" as a fifth ("quintessential") element lighter than all the above, and also noting that this lightest of elements has been trapped in the "heaviness" of matter. This also recalls the Manichaean notion that the lightest of the elements of light are contained in the densest elements of earth, and that the lightest elements of mind are contained in the densest elements of body. For Augustine, the resurrection of the body and its physical ascension into heaven, then, requires adjusting the ratio of soul and body, light and heavy elements, so that the resurrected body is capable of rising through the air (de civ. Dei 22:11).

The most perplexing conundrum about the passibility of the body, however, was the question of a cannibal who has eaten the flesh of someone else's body. How can the physical mass of victim's body be sorted out? "Shall this return to the man whose flesh it first was, or to him whose flesh it afterwards became?" (de civ. Dei 22:12). The answer to this and a host of related question is provided in Chapter 20:

From all that we have thus considered, and discussed with such poor ability as we can command, we gather this conclusion, that in the resurrection of the flesh the body shall be of that size which it either had attained or should have attained in the flower of its youth, and shall enjoy 
the beauty that arises from preserving symmetry and proportion in all its members. And it is reasonable to suppose that, for the preservation of this beauty, any part of the body's substance, which, if placed in one spot, would produce a deformity, shall be distributed through the whole of it, so that neither any part, nor the symmetry of the whole, may be lost, but only the general stature of the body somewhat increased by the distribution in all the parts of that which, in one place, would have been unsightly. Or if it is contended that each will rise with the same stature as that of the body he died in, we shall not obstinately dispute this, provided only there be no deformity, no infirmity, no languor, no corruption,nothing of any kind which would ill become that kingdom in which the children of the resurrection and of the promise shall be equal to the angels of God, if not in body and age, at least in happiness.

(de civ. Dei 22:20; trans. Bettenson 1984).

Augustine is saying that the nature of the resurrected body is that of the ordinary body, but transformed into the optimum perfection it reached or ought to have reached in its earthly life. Thus the image of Christ to which Christians are to be conformed is not simply to be understood as intellectual or spiritual perfection, but as the natural, moral and aesthetic perfection of the flesh. This point is made clear in de civ. Dei 19, which claims that blemishes that detract from beauty will be removed in the resurrection, but that blemishes such as the wounds of Christ, which are evidence of the moral beauty of the body, will remain. 4

Although Augustine never speaks of Jesus as having a perfect physical form, the implication of his discussion of the resurrection body is that perfection is somehow more compatible with or more indicative of the divine nature, and that this perfection is an attribute that can be predicated of physical bodies. Augustine notes that the "perfect" age for a body is 30 years (de civ. Dei 22.15), and it is doubtless far from a coincidence that this is the age at which Jesus achieved his resurrection body.

This approach to Augustinian theology stands in contrast to the majority of readings which treat Augustine primarily in terms of human psychology and salvation history. But although the drama of fall and redemption for Augustine is chiefly to be understood as an historical drama affecting uniquely the human species, this does not mean that it does not have natural or environmental dimensions precisely because, in the Christian scheme, the creation of Adam is

${ }_{4} \mathrm{Cf}$. the many stories in the Zhuangzi of sages whose physical appearance is deformed. 
the culmination of the cosmic work of creation and Jesus Christ is understood as the unique incarnation of God. If the victory that Jesus' death is supposed to have won is simply a moral-in the sense of spiritual-victory then the resurrection of the body would have no meaning. Augustine's preoccupation with the question of morality must be grounded in the incontrovertible fact that the moral freedom that Jesus won for Christians was won not by his preaching but by the cosmicbody transactions of his incarnation, death and resurrection. The cosmic transfiguring of the body through Jesus' incarnation and resurrection is the only true foundation for the moral perfection that so intoxicated Augustine.

The Christian tradition has perhaps tended to avoid such overtly materialist or cosmological readings of its tradition, and the study of religions has generally colluded with this theological tendency in concentrating on the symbolic aspect of myth and ritual. But this distinction between a theoretical, cultural spirit and a practical, material world, a distinction that is institutionalized in our universities, is surely unhelpful. Construing the relations between spirits and environments and between symbols and cosmos is surely a necessary theological task for the $21^{\text {st }}$ century.

\section{References}

Bettenson, Henry. trans. 1984. Concerning the City of God Against the Pagans; with an introduction by John O'Meara. New York: Penguin Books.

Durkheim, Emile. 1995. The Elementary Forms of Religious Life. Translated with an introduction by Karen E. Fields. New York: The Free Press.

Girardot, N. J., Liu Xiaogan and James Miller, eds. 2001. Daoism and Ecology: Ways within a Cosmic Landscape. Cambridge, MA: Harvard University Center for the Study of World Religions, distributed by Harvard University Press.

Hahn, Thomas. 200o. "Daoist Sacred Sites" in Daoism Handbook edited by Livia Kohn, 683-708. Leiden: E. J. Brill.

LaFargue, Michael. 2001. "Nature' as Part of Human Culture in Daoism” in Daoism and Ecology: Ways within a Cosmic Landscape edited by N. J. Girardot, James Miller and Liu Xiaogan. Cambridge, MA: Harvard University Center for the Study of World Religions, distributed by Harvard University Press. 
Neville, Robert Cummings. 1995. Normative Cultures. Albany: State University of New York Press.

Miller, James. 2000. The Economy of Cosmic Power: A Theory of Religious Transaction and a Comparative Study of Shangqing Daoism and the Christian Religion of Augustine of Hippo. PhD Dissertation. Boston, MA: Boston University. . 2001. "Envisioning the Daoist Body in the Economy of Cosmic Power." Daedalus 130.4: 265-282. . 2003. "Daoism and Nature" in Nature Across Cultures: Non-Western Views of Nature and Environment edited by Helaine Selin. The Hague: Kluwer Academic Press. 